\title{
Kinetic study on thermal decomposition of woods in oxidative environment
}

\author{
D.K. Shen ${ }^{a}$, S. Gu ${ }^{a, *}$, K.H. Luo ${ }^{\text {a }}$, A.V. Bridgwater ${ }^{\text {b }}$, M.X. Fang ${ }^{c}$ \\ a School of Engineering Science, University of Southampton, Highfield, Southampton SO17 1BJ, United Kingdom \\ ${ }^{\mathrm{b}}$ School of Engineering and Applied Science, Aston University, Aston Triangle, Birmingham B4 7ET, United Kingdom \\ ${ }^{\mathrm{c}}$ Institute for Thermal Power Engineering, Zhejiang University, Hangzhou 310027, PR China
}

\section{A R T I C L E I N F O}

\section{Article history:}

Received 25 August 2008

Received in revised form 17 October 2008

Accepted 21 October 2008

Available online 17 November 2008

\section{Keywords:}

Thermal decomposition

Biomass

Hemi-cellulose

Cellulose

Kinetics

\begin{abstract}
A B S T R A C T
The purpose of this work is to gain knowledge on kinetics of biomass decomposition under oxidative atmospheres, mainly examining effect of heating rate on different biomass species. Two sets of experiments are carried out: the first set of experiments is thermal decomposition of four different wood particles, namely aspens, birch, oak and pine under an oxidative atmosphere and analysis with TGA; and the second set is to use large size samples of wood under different heat fluxes in a purpose-built furnace, where the temperature distribution, mass loss and ignition characteristics are recorded and analyzed by a data post-processing system. The experimental data is then used to develop a two-step reactions kinetic scheme with low and high temperature regions while the activation energy for the reactions of the species under different heating rates is calculated. It is found that the activation energy of the second stage reaction for the species with similar constituent fractions tends to converge to a similar value under the high heating rate.
\end{abstract}

(c) 2008 Elsevier Ltd. All rights reserved.

\section{Introduction}

Biomass is one of the major energy sources today, contributing approximately $14 \%$ of the world annual energy consumption in comparison to $12 \%$ from coal and $15 \%$ from gases [1]. As a renewable source of energy, biomass offers environmental benefits with easy availability of feedstocks including agricultural and forestry residues and wastes. There are growing interests of developing efficient biomass thermal conversion technologies worldwide to combat climate change and provide the solutions for current energy crisis. Biomass thermochemical conversion processes including combustion, gasification and liquefaction are employed for power generation [2] and production of liquid biofuels [3-5], chemicals [6,7] and charcoal [1,8-11] which can be used as activated carbon [12] for absorbent as well as domestic fuels. A good understanding of the decomposition of biomass during thermochemical conversion is important for developing efficient processing technology.

It is known that the biomass is mainly composed of hemi-cellulose, cellulose and lignin, which decompose at the temperature range of $225-325,305-375$ and $250-500{ }^{\circ} \mathrm{C}$, respectively [11]. The variation of constituent fractions in biomass gives different thermal behaviour and products are generally from three categories, namely non-condensible gases, heavy volatiles (called tar) and char [22]. Most reported studies about the kinetics of biomass

\footnotetext{
* Corresponding author.

E-mail addresses: s.gu@soton.ac.uk,ds1t07@soton.ac.uk (S. Gu).
}

decomposition $[1,6,10,11,14-21]$ focus on pyrolyzing cellulosic materials under inert atmospheres using either experimental or theoretical methods. Di Blasi C [23] and Varhegyi [24] have given good reviews about the kinetic schemes for thermal decomposition of biomass and its constituents under inert atmospheres. Most recent research is to study biomass decomposition in oxidative environments and some work has been reported [13,25-28]. The oxidative process is claimed to have two steps: the first step is volatilization of the main biomass constituents and production of char residue at low temperature; the second step includes the decomposition of lignin and the combustion of the charcoal generated in the early stage [28], which has considerable difference from the inert atmosphere as the presence of oxygen causes additional complexities, such as the enhancement of the decomposition of the materials at low temperature and promotions of the char residue combustion [25].

It is believed [25] that the kinetics of decomposition of biomass under inert and oxidative atmospheres are influenced by different equipment, experimental conditions (temperature, pressure and heating rate), the physical properties of materials (moisture content and particle size) and the chemical composition of the solid (three main constituents and inorganic components). The effects of the above factors on the behaviour of biomass decomposition under inert atmospheres have been mostly investigated while there is not sufficient information available for oxidative environments. The purpose of this study is to obtain a good knowledge on kinetics of biomass decomposition under oxidative atmospheres, mainly examining the effects of heating rate to different biomass 


\begin{tabular}{|c|c|c|c|}
\hline \multicolumn{4}{|c|}{ Nomenclature } \\
\hline$T$ & temperature (K) & 0 & initial \\
\hline$t$ & time $(\mathrm{s})$ & $\infty$ & final or infinite \\
\hline$M$ & mass $(\mathrm{kg})$ & \multirow{2}{*}{\multicolumn{2}{|c|}{ Greek letters }} \\
\hline$A$ & pre-exponential factor $\left(\mathrm{s}^{-1}\right)$ & & \\
\hline E & activation energy $\left(\mathrm{J} \mathrm{mol}^{-1}\right)$ & $\alpha$ & mass fraction at time $t$ \\
\hline$R$ & universal gas constant $\left(8.3145 \mathrm{~J} \mathrm{~mol}^{-1} \mathrm{~K}^{-1}\right)$ & $\beta$ & heating rate $\left(\mathrm{K} \mathrm{s}^{-1}\right)$ \\
\hline \multicolumn{4}{|c|}{ Subscripts } \\
\hline $\mathrm{s}$ & solid & & \\
\hline $\mathrm{i}$ & reaction or stage & & \\
\hline
\end{tabular}

species. The kinetics of this thermal decomposition is more related to combustion process, therefore the work will contribute to the development of efficient biomass combustion applications. Two sets of experiments are carried out: the first set of experiments is thermal decomposition of four different wood particles under an oxidative atmosphere and analysis with thermogravimetric analyzer (TGA); and the second set is to use large size samples of wood under different heat fluxes in a purpose-built furnace, where the temperature distribution, mass loss and ignition characteristics are recorded and analyzed by a data post-processing system. The experimental data is then used to develop a two-step reaction kinetic scheme while the activation energy for the reactions of the species under different heating rates is calculated.

\section{Experimental setup}

TGA experiment of solid fuel is performed using a Mettler Toledo TGA/SDTA 8951E thermo analyzer under an oxidative atmosphere. Four different wood samples, namely aspens, birch, oak and pine tested in the experiment are tested and their properties are detailed in Table 1. It needs to be noted in Table 1 that the sum of the element contents is not $100 \%$ since the sample of wood is not pre-dried. The element content is obtained from a Mettroler element and proximate analyzer. Through carefully sieving and mortaring, the particles are reduced to less than $0.5 \mathrm{~mm}$ $(500 \mu \mathrm{m})$ to ensure the heat transfer rate within the kinetic regime of the decomposition [22,24], and the initial mass of samples is

Table 1

Properties of the woods tested in the experiments.

\begin{tabular}{lllll}
\hline & Pine & Aspens & Birch & Oak \\
\hline $\begin{array}{l}\text { Density }\left(\mathrm{kg} \mathrm{m}^{-3}\right) \\
\text { Low heating value }\end{array}$ & 509 & 514 & 796 & 844 \\
$\quad\left(\mathrm{~kJ} \mathrm{~kg}^{-1}\right)$ & 16,805 & 18,793 & 15,475 & 18,872 \\
Proximate analysis (as received, \%) & & & \\
$\quad$ Moisture & 12.9 & 8.19 & 11.39 & 8.78 \\
$\quad$ Volatiles & 71.49 & 80.37 & 74.36 & 76.82 \\
Fixed carbon & 15.31 & 11.03 & 13.49 & 14.16 \\
Ash & 0.3 & 0.41 & 0.76 & 0.24 \\
Ultimate analysis (as received, \%) & & & \\
$\quad$ Carbon & 41.89 & 45.84 & 44.41 & 45.37 \\
$\quad$ Hydrogen & 4.5 & 5.22 & 3.48 & 5.03 \\
$\quad$ Nitrogen & 0.22 & 0.36 & 0.27 & 0.28 \\
$\quad$ Oxygen & 40.19 & 39.97 & 36.65 & 41.29 \\
Sulfur & 1 & 0.01 & $/$ & 0.01 \\
Ratio of C:H:O & $1: 1.29: 0.72$ & $1: 1.37: 0.65$ & $1: 0.94: 0.62$ & $1: 1.33: 0.68$ \\
$\quad($ mol mol & & & & \\
Constituent analysis (\%) & & & & \\
$\quad$ Hemi-cellulose & 15.37 & 19.06 & 24.79 & 28.97 \\
$\quad$ Cellulose & 52.10 & 60.70 & 56.47 & 53.95 \\
Lignin & 27.45 & 14.80 & 12.17 & 9.43 \\
Inorganic materials & 5.08 & 5.44 & 6.57 & 7.65 \\
\hline
\end{tabular}

kept less than $5 \mathrm{mg}$ to avoid possible effect on mass and heat transfer during the process of biomass decomposition [29]. The samples are heated from 40 to $800^{\circ} \mathrm{C}$ at heating rate of $10,30,60,80$ and $100 \mathrm{~K} \mathrm{~min}^{-1}$. During the experiment the reactor of TGA is flushed with $60 \mathrm{ml} \mathrm{min}^{-1}$ air to maintain an oxidative atmosphere for thermal decomposition of the particles.

The furnace experiment is carried out in a purpose-built pyrolysis and combustion system shown in Fig. 1. The wood samples are made as flat panels with a surface area of $100 \mathrm{~mm} \times 100 \mathrm{~mm}$ and thickness of $15 \mathrm{~mm}$. The sample is fixed horizontally with a sample holder and heated by a cone-shaped calorimeter (supplying heat flux from 0 to $80 \mathrm{~kW} \mathrm{~m}^{-2}$ ) under different atmospheric conditions inside a $580 \mathrm{~mm} \times 580 \mathrm{~mm} \times 460 \mathrm{~mm}$ refractory steel furnace. As shown in Fig. 1, only the top surface is subjected to uniform heat flux from 20 to $60 \mathrm{~kW} \mathrm{~m}^{-2}$, while the other sides are insulated with asbestos. Thermocouples are placed along the centreline with various depths below the surface such as 1,7 and $14 \mathrm{~mm}$. Two thermocouples are placed in around the centre of solid surface at a depth of $1 \mathrm{~mm}$, where no significant reading difference is observed between the two points during the experiment. Continuous measurement of the mass loss of the solid is done by an electronic scale connected to the sample holder. The temperature and the mass of the solid including the sample holder are recorded every second. Each wood is tested at least twice to reduce any possible error.

\section{Results and discussion}

\subsection{TGA results}

The TG curves for the samples under different heating rates are obtained using Gaussian function for the original experimental data from the thermo analyzer, then the DTG curves are achieved by differentiating TG curve by temperature. The TG and DTG curves for the four species under the heating rate of $10 \mathrm{~K} \mathrm{~min}^{-1}$ are shown in Figs. 2 and 3. It is apparent that the DTG curves are separated into two stages with the first one in the range of $200-370^{\circ} \mathrm{C}$ and the second stage in the range of $370-490^{\circ} \mathrm{C}$. Different explanations for the curves are available today. Bilbao et al. [25] claim that the first stage is attributed to the volatilization of three main constituents and the stage two is assigned to the combustion of char residue formed previously, which is further agreed by Fang et al. [28] and Liu [30], and we are more inclined to this explanation. Safi et al. [13] and Orfao [16] explain the mass loss phenomena as the first stage caused by the combination of the totally decomposition of hemi-cellulose and cellulose and partially decomposition of lignin, and the second stage corresponding to the decomposition of the remaining lignin and combustion of the char residues. Apparently, the presence of oxygen has caused the complexity, however, it is agreed that the decomposition of hemi-cellulose and cellulose mainly contributing to the mass loss of the first stage $\left(200-370{ }^{\circ} \mathrm{C}\right)$. It is also observed in Fig. 3 that there is a "shoulder peak" in the 


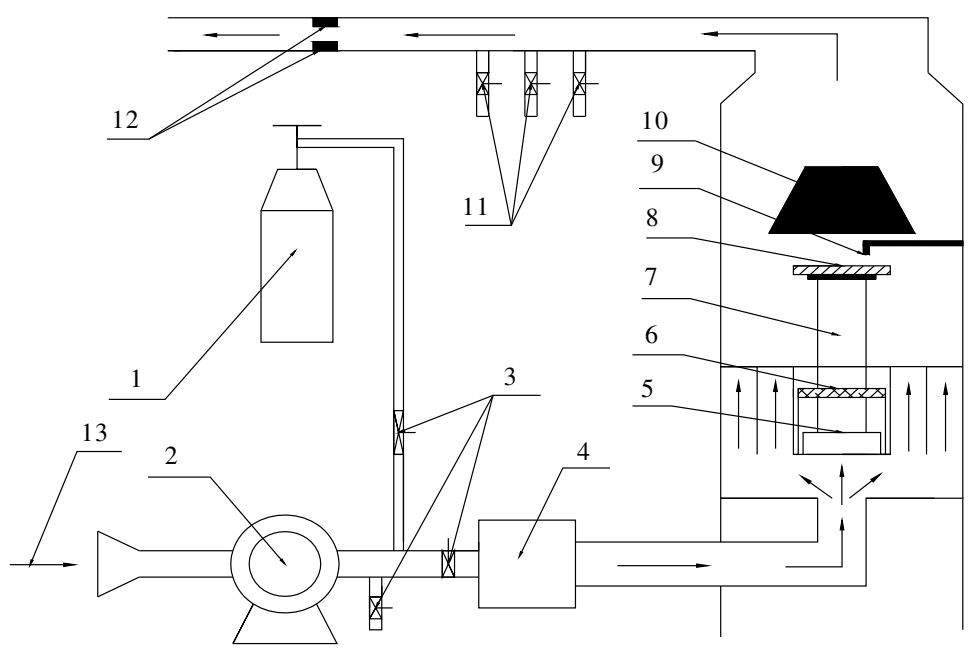

1. Nitrogen, 2. Electromotor, 3. Valves, 4. Gas mixing room, 5. Electronic balance,

6. Insulating board, 7. Specimen holder, 8. Sample, 9. Electrical spark,

10. Cone calorimeter, 11. Electromagnetic valve, 12. Flowmeter, 13. Air

Fig. 1. Pyrolysis and combustion experimental system.

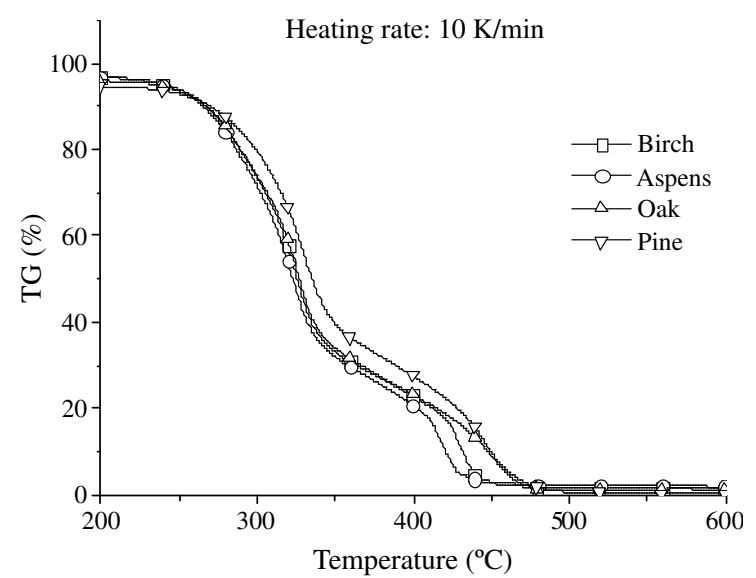

Fig. 2. The TG curves of several species of wood under heating rate of $10 \mathrm{~K} \mathrm{~min}^{-1}$.

first stage of the DTG curve at around $280^{\circ} \mathrm{C}$ for aspens, birch and oak, which is attributed to the decomposition of hemi-cellulose as concluded in most studies $[13,16,25,30]$. However, the "shoulder" peak is not obviously noticed on the DTG curve of pines, due to its lowest content of hemi-cellulose among the four species. It is known that hemi-cellulose is formed by different compositions of the polysaccharides. Since $80-90 \mathrm{wt} \%$ of hemi-cellulose is composed of 4-O-methyl glucoronoxylan for the deciduous wood (such as birch and oak) whereas $60-70$ wt\% of glucomannan and 15$30 \mathrm{wt} \%$ of arabinogalactan are contained in the hemi-cellulose of coniferous wood (pine) [11], it is found by Ramiah [31] that the hemi-cellulose of deciduous woods reacts faster than the coniferous woods. Another explanation for the "non-shoulder peak" DTG curve for pine (coniferous wood) could be that its hemi-cellulose contains too much glucomannan and arabinogalactan, which postpone the process of thermal decomposition of hemi-cellulose. In that case, the peak of hemi-cellulose decomposition is concealed by that of cellulose, while the temperature demarcation for hemicellulose decomposition is overlapped with that of cellulose which dominates the first stage of thermal decomposition of biomass. As a result, the "shoulder peak" of DTG curve of pine disappears

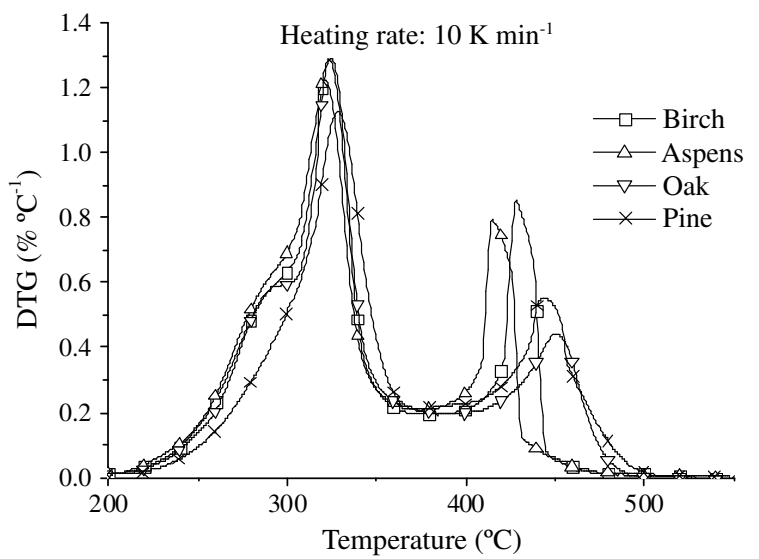

Fig. 3. The DTG curves of several species of wood under heating rate of $10 \mathrm{~K} \mathrm{~min}^{-1}$.

$[13,21,24,32]$. The second stages of DTG curves for the four species is noticeably different from each other as seen in Fig. 3 and the normalized DTG peak values are varied from 0.4 to $0.8 \% \mathrm{~K}^{-1}$ at a temperature range between 420 and $460{ }^{\circ} \mathrm{C}$ (Table 2). That is mainly caused by the different constituent fractions among four species as shown in Table 1, especially the content of lignin (the significant contributor for the production of char residue), leading to different processes of char formation which directly affects thermal decomposition of biomass in the second stage under an oxidative atmosphere.

The TG and DTG curves for the four species under the high heating rate of $100 \mathrm{~K} \mathrm{~min}^{-1}$ are shown in Figs. 4 and 5. Two stages of thermal decomposition are also visible in the DTG curves where the stage one is from 220 to $410{ }^{\circ} \mathrm{C}$ and the stage two is from 410 to $590{ }^{\circ} \mathrm{C}$, both are in higher temperature ranges than that those under the low heating rate of $10 \mathrm{~K} \mathrm{~min}^{-1}$. It is interpreted as that thermal decomposition under the high heating rate is affected by the heat transfer inside the particles as a result of the sharp temperature gradient between the particle and the surrounding, as well as the kinetic regime $[24,25,30]$. Thus, the process of thermal decomposition of biomass is postponed and the 
Table 2

The characteristic values of the DTG curve for the different species under the low and high heating rate.

\begin{tabular}{lllllll}
\hline $\begin{array}{l}\text { Heating rate } \\
\left(\mathrm{K} \mathrm{min}^{-1}\right)\end{array}$ & Species & \multicolumn{6}{c}{ The peak values of the DTG curve } \\
\cline { 2 - 7 } & & $T_{1}\left({ }^{\circ} \mathrm{C}\right)$ & $T_{2}\left({ }^{\circ} \mathrm{C}\right)$ & $X_{1}\left(\%{ }^{\circ} \mathrm{C}^{-1}\right)$ & $X_{2}\left(\%{ }^{\circ} \mathrm{C}^{-1}\right)$ & $X_{\infty}(\%)$ \\
\hline 10 & Pine & 329 & 443 & 1.13 & 0.55 & 0.58 \\
& Aspens & 321 & 415 & 1.23 & 0.79 & 1.63 \\
& Birch & 323 & 428 & 1.29 & 0.85 & 1.26 \\
& Oak & 325 & 450 & 1.29 & 0.44 & 1.03 \\
100 & Pine & 367 & 486 & 0.82 & 0.14 & 1.48 \\
& Aspens & 343 & -- & 0.87 & -- & 0.98 \\
& Birch & 350 & -- & 0.80 & -- & 2.26 \\
& Oak & 350 & -- & 0.84 & -- & 4.08 \\
\hline
\end{tabular}

$\overline{T_{1} \text { - temperature of the first peak of the DTG curve; } T_{2} \text { - temperature of the second }}$ peak of the DTG curve; $X_{1}$ - mass loss rate of the first peak of the DTG curve; $X_{2}-$ mass loss rate of the second peak of the DTG curve; $X_{\infty}$ - the residue content of the solid at the final temperature and "--" - not apparent.

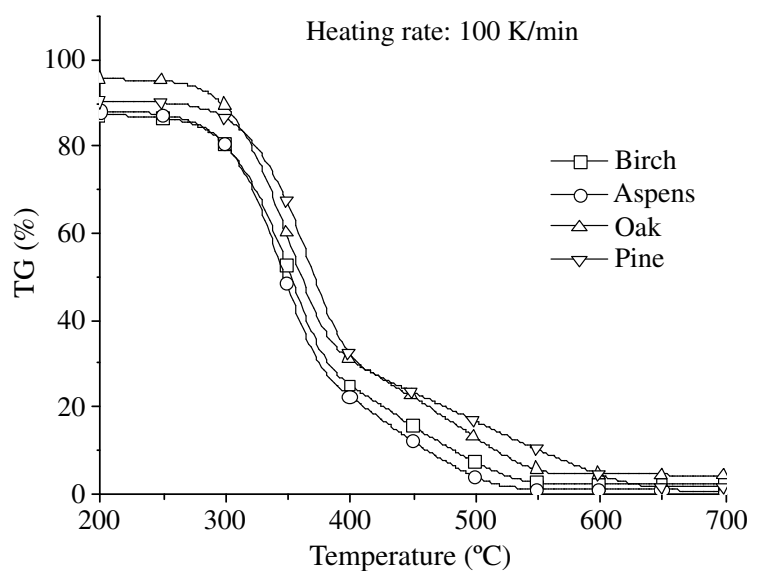

Fig. 4. The TG curves of several species of wood under heating rate of $100 \mathrm{~K} \mathrm{~min}^{-1}$.

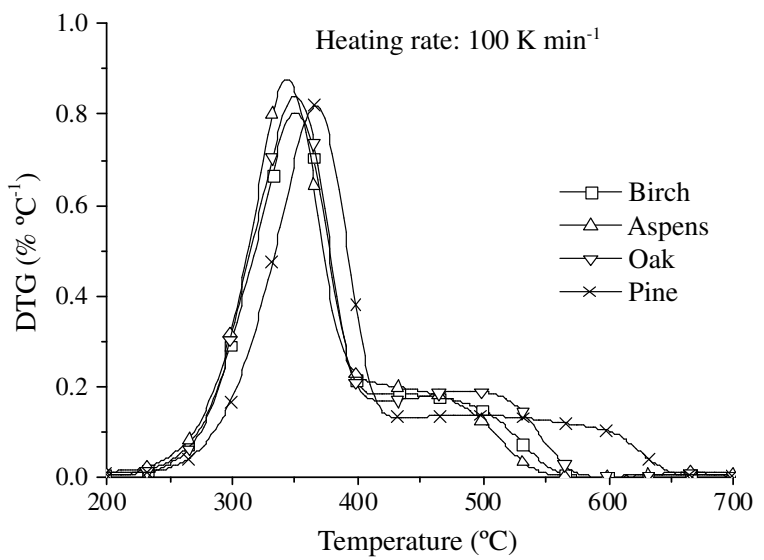

Fig. 5. The DTG curves of several species of wood under heating rate of $100 \mathrm{~K} \mathrm{~min}^{-1}$

peaks of the DTG curves shift towards the higher temperatures (Table 2). The resemblance among the DTG curves for aspens, birch and oak is due to similar constituent fractions. On the other hand, the high content of lignin in pine decomposes in a much wider range of temperatures and produces more char residue for the second stage combustion, which gives rises to the different thermal decomposition of pine in the second stage. No "shoulder peak" phenomenon is noticeable in the first stage of the DTG curves among all four species in Fig. 5. A possible explanation could be that thermal decomposition of hemi-cellulose is greatly delayed under high heating rates and the first stage phenomenon is overwhelmed by the more reactive cellulose. Such suggestion needs to be verified by more experiment for the thermal decomposition of three constituents under different heating rate and will be carried out in our future research.

\subsection{Kinetic model}

A two-stage reaction kinetic scheme is proposed for the thermal decomposition of biomass under an oxidative atmosphere, representing the DTG curves described above. The kinetic scheme is illustrated as the following two separate reactions in reference to the work by Liu [30]:
A (Solid) $\rightarrow$ B (Char) + C1 (Gas)
(The first stage)
B $($ Char $) \rightarrow$ C2 (Gas) + D (Ash)
(The second stage)

The kinetics of the decomposition reactions are largely described by first-order Arrhenius law [33,34]. The study by Liu [30] concluded that the best linear regression of the Arrhenius function is achieved when the order of the reactions of oxidative pyrolysis of biomass is equal to one. Based on the above theory, the kinetic parameters are calculated from the linear regression curve with the correlation factors (almost all above 0.99). In this paper, the process of thermal decomposition is divided into two separate reactions and each is also governed by first-order Arrhenius law [28].

The mass loss fraction $\alpha$ for the stage is defined as:

$\alpha_{\mathrm{i}}=\frac{M_{\mathrm{i} 0}-M_{\mathrm{i}}}{M_{\mathrm{i} 0}-M_{\mathrm{i} \infty}}$

The kinetics of the reaction is described as:

$\frac{\mathrm{d} \alpha_{\mathrm{i}}}{\mathrm{d} t}=k_{\mathrm{i}} f\left(\alpha_{\mathrm{i}}\right)$

where

$k=A \exp (-E / R T)$

$f(\alpha)=1-\alpha$

Eq. (2) could be transformed to:

$\frac{\mathrm{d} \alpha}{f(\alpha)}=\frac{k}{\beta} \mathrm{d} T$

And then the process of thermal decomposition of wood under an oxidative atmosphere could be mathematically described as:

$\frac{\mathrm{d} \alpha}{\mathrm{d} T}= \begin{cases}\frac{M_{10}-M_{1 \infty}}{M_{10}-M_{2 \infty}} \frac{\mathrm{d} \alpha_{1}}{\mathrm{~d} T} & M_{10}<\alpha_{1}<M_{1 \infty} \\ \frac{M_{20}-M_{2 \infty}}{M_{10}-M_{2 \infty}} \frac{\mathrm{d} \alpha_{2}}{\mathrm{~d} T} & M_{20}<\alpha_{2}<M_{2 \infty}\end{cases}$

where $M_{\mathrm{i} 0}$ is the initial mass of solid at the beginning of reaction i, $M_{\mathrm{i} \infty}$ is the residue mass at the end of reaction i, $\beta$ is the heating rate, $k$ is the reaction rate and the kinetic parameter activation energy $E$ and pre-exponential factor $A$.

An integration function of Eq. (4) is shown as below:

$g(\alpha)=\int_{0}^{\alpha} \frac{\mathrm{d}(\alpha)}{f(\alpha)}=\frac{A}{\beta} \int_{T_{0}}^{T} \exp (-E / R T) \mathrm{d} T$

Eq. (6) is integrated by using Caots-Redfern method [35]:

$\ln \left[\frac{g(\alpha)}{T^{2}}\right]=\ln \left\{\frac{A R}{\beta E}\left[1-\frac{2 R T}{E}\right]\right\}-\frac{E}{R T}$ 
where

$g(\alpha)=-\ln (1-\alpha)$

As the term of $\frac{2 R T}{E}$ can be neglected since it is much less than one, Eq. (7a) could be simplified as:

$\ln \left[\frac{g(\alpha)}{T^{2}}\right]=\ln \left(\frac{A R}{\beta E}\right)-\frac{E}{R} \cdot \frac{1}{T}$

The term of $\ln \left[\frac{g(\alpha)}{T^{2}}\right]$ varies linearly with $\frac{1}{T}$ as slope of the line is $-\frac{E}{R}$ which is plotted in Figs. 6 and 7. Meanwhile, the intercept of the line with $y$-axis is related to the pre-exponential factor $A$. Both the activation energy $E$ and pre-exponential factor $A$ can be determined by the slope and intercept of the line. However, each step of thermal decomposition of wood under an oxidative atmosphere is considered to be a single reaction in this analytical method. Thus, the calculated value of activation energy is an averaged value and may be a little smaller than other methods [36].

The activation energy $(E)$ for the two-step reactions of thermal decomposition of different species under different heating rates is calculated and compared in this study. The activation energy of the first reaction for different species in the low temperature stage is presented in Fig. 8. It could be found that the activation energy of the first reaction for the species is not too much different from each other and varied slightly (from 104 to $125 \mathrm{~kJ} \mathrm{~mol}^{-1}$ ) as the heating rate increased. Comparably, the activation energies for

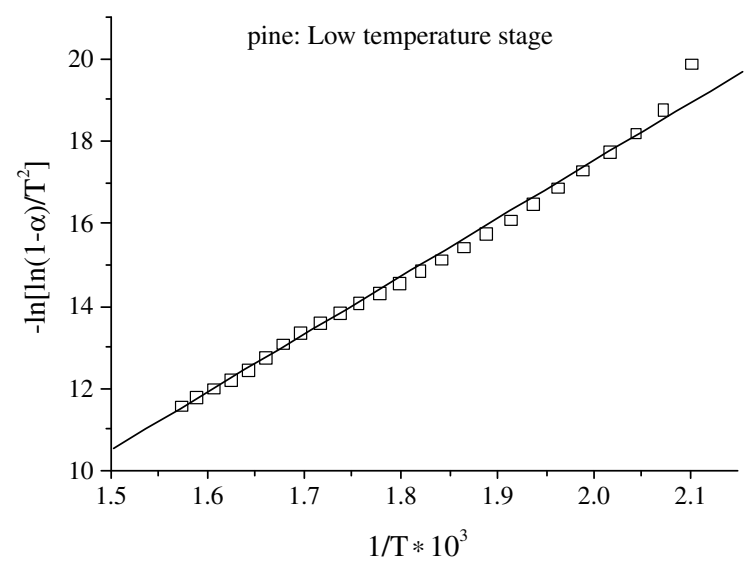

Fig. 6. The linear regression curve of $\ln \left[\ln (1-\alpha) / T^{2}\right]$ vs $1 / T$ for the low temperature stage.

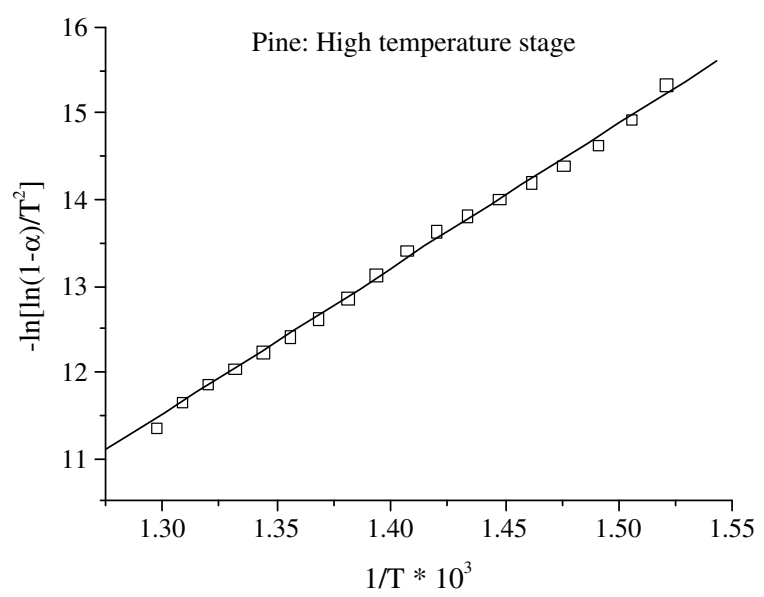

Fig. 7. The linear regression curve of $\ln \left[\ln (1-\alpha) / T^{2}\right]$ vs $1 / T$ for the high temperature stage.

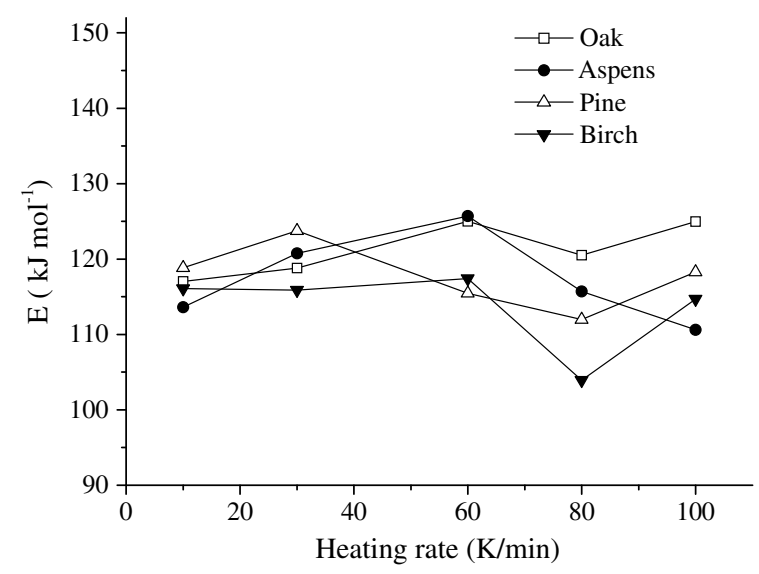

Fig. 8. Comparison of activation energy for the first stage reaction of the four species under different heating rates.

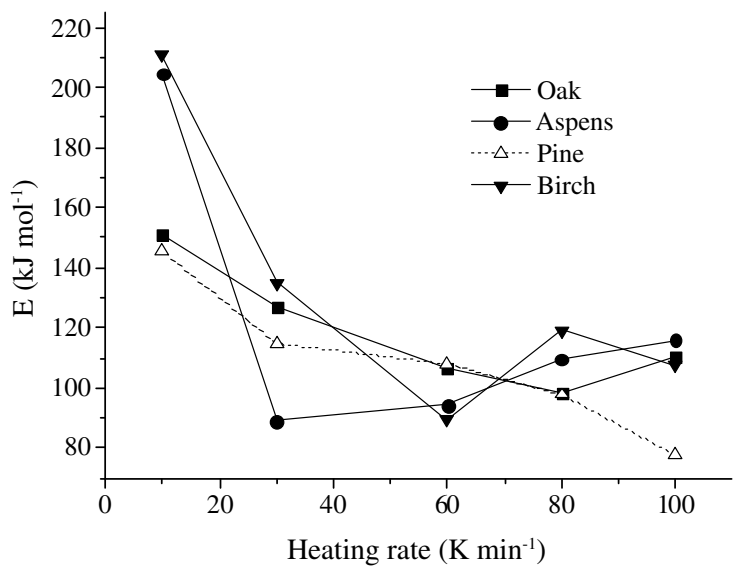

Fig. 9. Comparison of activation energy for the second stage reaction of the four species under different heating rates.

the second stage reaction among the species are observed more differently under the lower heating rate (from 89 to $220 \mathrm{~kJ} \mathrm{~mol}^{-1}$ ), and vary more narrowly when the heating rate increases (Fig. 9). It may be interpreted that the heat transfer inside the particle is enhanced as the heating rate increases, thus the reactivity of the wood and its constituents is reduced in comparison to that under lower heating rate at the same temperature. It needs to be noted that the high heating rate will not give sufficient time for heat transferred to the centre of the particle and leave high temperature gradient within the particle. For the same surface temperature for the particle, the low heating rate shows better reactivity of the wood as the temperature gradient with the particle is more uniform. It is also found in Fig. 9 that the activation energies of the second stage reaction for the species, except for pine, arrive to about the same value $\left(110 \mathrm{~kJ} \mathrm{~mol}^{-1}\right)$ as the heating rate increases. This implies that the species with the similar constituent fractions would undergo the similar process of thermal decomposition under the high heating rate, as confirmed by the experimental analysis before.

\subsection{Furnace experiment}

Thermal decomposition for large wood samples is studied under an air atmosphere in the purpose-built pyrolysis and combustion experimental system (Fig. 1). The effects of heat fluxes on the behaviour of thermal decomposition (especially the temperature 
distribution and mass loss rate) of the biomass species are investigated in this section.

The temperature distribution and mass loss rate of birch under heat flux of $20 \mathrm{~kW} \mathrm{~m}^{-2}$ is shown in Fig. 10. It is found that the wood sample begins to lose its water as the temperature exceeded $80^{\circ} \mathrm{C}$. Up to $240^{\circ} \mathrm{C}$, the solid has a slow weight loss in glassy transition, while the evolved gases are not ignitable. From 240 to $320^{\circ} \mathrm{C}$, the pyrolysis is thought to be endothermic, resulting in evolution of mixtures primarily composed of carbon dioxide and water vapor. From 320 to $450^{\circ} \mathrm{C}$, the wood specimen pyrolyzes rapidly and the rate of release of flammable volatiles greatly increases at around $500 \mathrm{~s}$; in the mean meanwhile, more charcoal is produced on the top surface layer and building up the resistance to the heat transfer into the inner layers of solid. The structural change is represented by the shrinkage and cracking in the char layer at about $800 \mathrm{~s}[37,38]$, the pyrolysis of the solid inside accelerates and the bottom temperature starts to rise quickly, and then the mass loss rate increases to reach the second peak at about $970 \mathrm{~s}$.

The top surface temperature and mass loss rate of the sample for four species under low heat flux of $20 \mathrm{~kW} \mathrm{~m}^{-2}$ are compared in Figs. 11 and 12. It is found in Fig. 11 that the top surface temper-

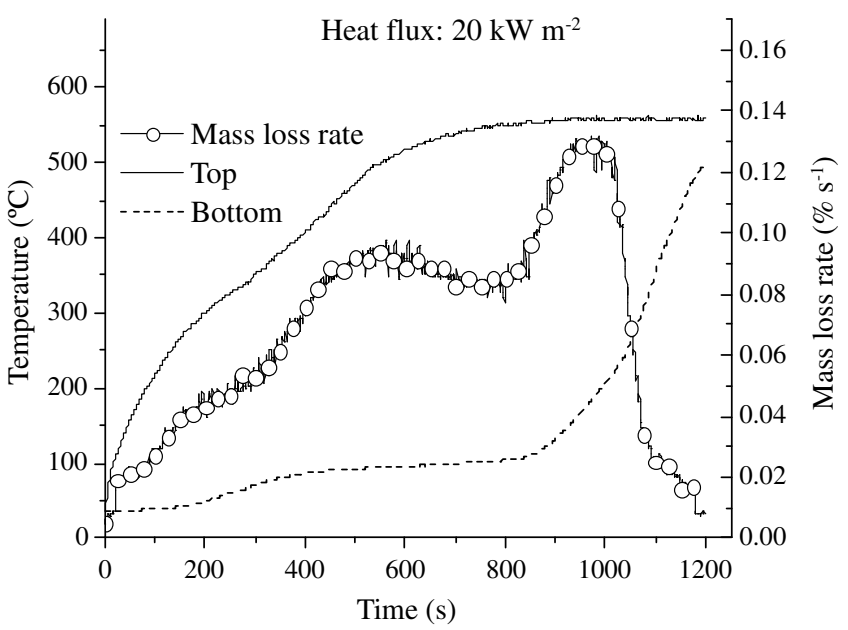

Fig. 10. The temperature distribution and mass loss rate of birch under the heat flux of $20 \mathrm{~kW} \mathrm{~m}^{-2}$.

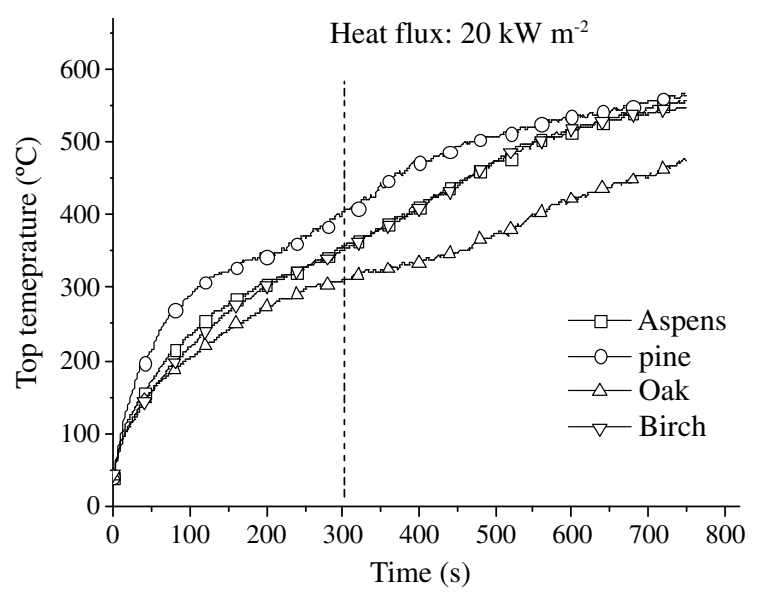

Fig. 11. The surface temperature of several species of woods under the heat flux of $20 \mathrm{~kW} \mathrm{~m}^{-2}$.

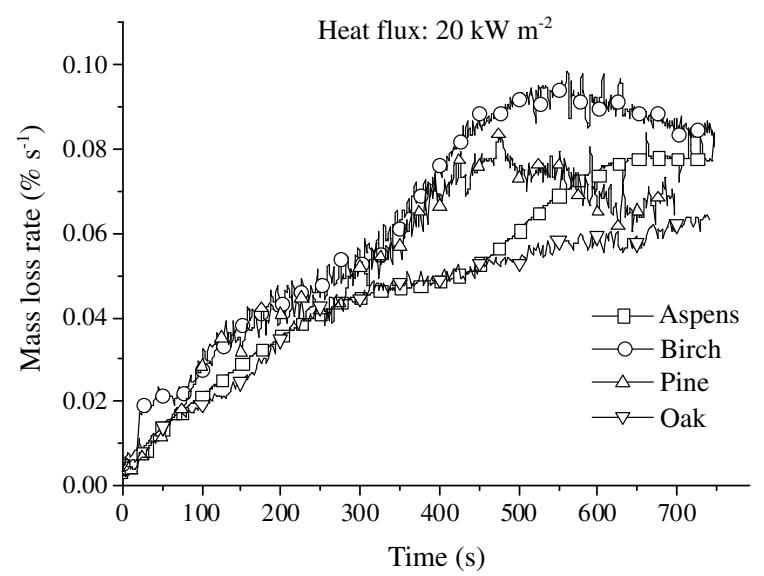

Fig. 12. The mass loss rate of several species of woods under the heat flux of $20 \mathrm{~kW} \mathrm{~m}^{-2}$

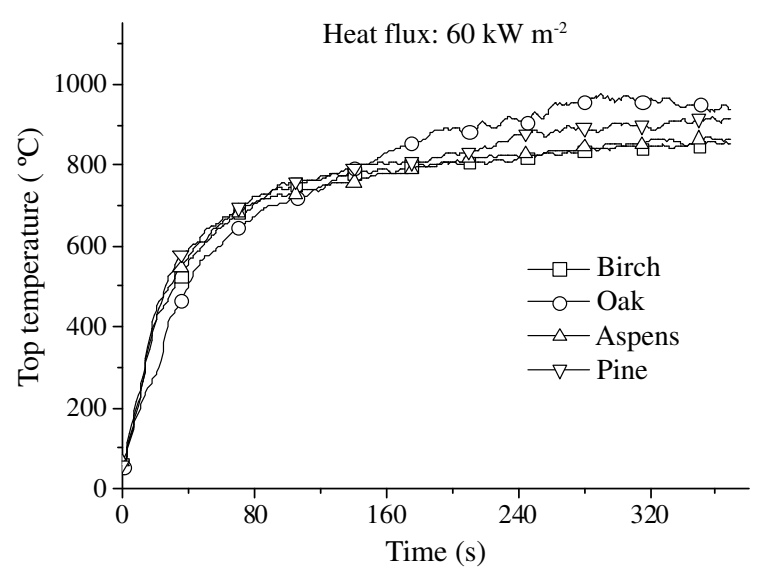

Fig. 13. The surface temperature of several species of woods under the heat flux of $60 \mathrm{~kW} \mathrm{~m}^{-2}$.

atures increase at different rate as the thermal conductivities of species vary $[39,40]$. For example, the top surface temperature is $290{ }^{\circ} \mathrm{C}$ for oak, $330{ }^{\circ} \mathrm{C}$ for aspens and birch, and $390{ }^{\circ} \mathrm{C}$ for pine at the time of $300 \mathrm{~s}$. The degree of thermal decomposition of the samples is very different as a result of variation of heat conduction inside the samples, which is shown by the mass loss curves for the solid phase in Fig. 12. The different mass loss rate among the species is contributed by two main factors: the first is the different heat conduction process and temperature evolution history between the species; and the second is the different constituent fractions. The process of thermal decomposition of the large size wood samples under the low heat flux is influenced by the heat conduction as well as chemical kinetics [37], therefore, various species have different results.

The top surface temperatures of the samples under high heat flux of $60 \mathrm{~kW} \mathrm{~m}^{-2}$ are compared in Fig. 13 and the mass loss rates are shown in Fig. 14. It is noted that the profiles for the top surface temperatures and the mass loss rates among the species show very similar trend. It could be explained that the thermal decomposition of the solid under the high heating flux progresses rapidly within a thin layer of solid surface, and combustible volatiles release quickly and then generated a flaming ignition. The process is too fast to be controlled by the heat conduction, possibly by ablation-controlled mechanism as described by Martin [41]. In general, the process of thermal decomposition for different species under 


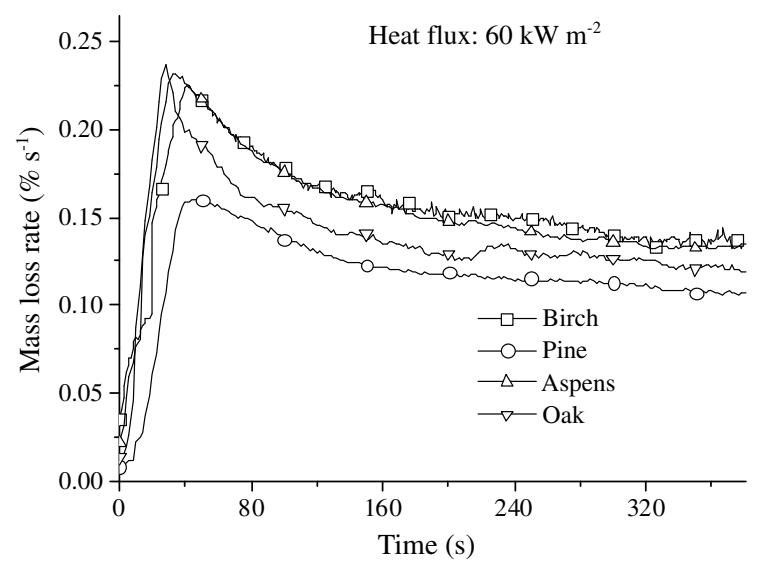

Fig. 14. The mass loss rate of several species of woods under the heat flux of $60 \mathrm{~kW} \mathrm{~m}^{-2}$.

the high heat flux shares a similar trend while the difference caused by constituent fractions is much less pronounced.

\section{Conclusions}

The thermal decomposition of different species of wood under an oxidative atmosphere was studied both experimentally and theoretically. A summary of findings are as follows:

(1) The TGA experiment confirms the previous report that the process of thermal decomposition of wood under an oxidative atmosphere is divided into two stages: the first stage is considered to be volatilization of the constituents and the second stage is contributed to combustion of char formed in the initial stage.

(2) The "shoulder peak" in the first stage of DTG curves is noticeable for the three species of deciduous wood under the low heating rate, but disappears as the heating rate increases. The "shoulder peak" of the DTG curves cannot be found for coniferous wood such as pine, due to its low content of hemi-cellulose and the composition of its hemicellulose not as reactive as that of the deciduous woods.

(3) Under the high heating rate, the process of thermal decomposition of the species with similar constituent fractions shows good resemblance in both the first and second stages. It is further confirmed by the two-stage reactions kinetic scheme proposed for the process. The activation energy of the first stage reaction for different species varies slightly at high heating rate, while the activation energy of the second stage reaction for the species ranges from 89 to $220 \mathrm{~kJ} \mathrm{~mol}^{-1}$ at the low heating rate. The activation energy for the deciduous wood species tends to converge to a similar value $\left(110 \mathrm{~kJ} \mathrm{~mol}^{-1}\right)$ during the second stage as the heating rate increases.

(4) In furnace experiment, the process of thermal decomposition of large size wood is found to be different from each other under the low heat flux, while the process is influ- enced by both heat conduction and kinetic regime. Under the high heat flux, the process of different species with the similar constituent fractions shows a good resemblance as the process may be ablation-controlled.

\section{Acknowledgements}

The authors gratefully acknowledge the financial support from the UK Department for Innovation Universities and Skills (DIUS) to the ICUK Proof of Concept award and the UK-China Fellowships for Excellence Award.

\section{References}

[1] Senneca O. Fuel Process Technol 2007;88:87-97.

[2] Kazagic A, Smajevic I. Energy 2007;32:2006-16.

[3] Asadullah M, Anisur Rahman M, Mohsin Ali M, Abdul Motin M, Borhanus Sultan M, Robiul Alam M, Sahedur Rahman M. Bioresour Technol 2007;99:44-50.

[4] Asadullah M, Anisur Rahman M, Mohsin Ali M, Abdul Motin M, Robiul Alam M. Fuel 2007;86:2514-20.

[5] Putun AE, Burcu Uzun B, Apaydin E, Putun E. Fuel Process Technol 2005;87:25-32.

[6] Valero A, Uson S. Energy 2006;31:1643-55.

[7] Orecchini F, Bocci E. Energy 2007;32:1006-11.

[8] Prauchner MJ, Pasa VMD, Mohallem NDS, Otani C, Otani S, Pardini LC. Biomass Bioenergy 2005;28:53-61.

[9] El-Hendawy VNA. J Anal Appl Pyrolysis 2006;75:159-66.

[10] Prins MJ, Ptasinski KJ, Janssen FJJG. J Anal Appl Pyrolysis 2006;77:35-40.

[11] Prins MJ, Ptasinski KJ, Janssen FJJG. J Anal Appl Pyrolysis 2006;77:28-34.

[12] Pastor-Villegas J, Pastor-Valle JF, Meneses Rodrigeuz JM, Garcia Garcia M. J Anal Appl Pyrolysis 2006;76:103-8.

[13] Safi MJ, Mishra IM, Prasad B. Thermochim Acta 2004;412(1-2):155-62.

[14] Antal MJ, Varhegyi G. Ind Eng Chem Res 1995;34:703-17.

[15] Momoh M, Eboatu A. Fire Mater 1996;20:173-81.

[16] Orfao JJM. Fuel 1999;78:349-58.

[17] Volker S, Rieckmann TH. J Anal Appl Pyrolysis 2002;62:165-77.

[18] Branca C, Blasi CD. J Anal Appl Pyrolysis 2003;67:207-19.

[19] Grioui N, Halouani K, Zoulalian A, Halouani F. Thermochim Acta 2006;440(1):23-30.

[20] Hosoya T, Kawamoto H, Saka S. J Anal Appl Pyrolysis 2007;80:118-25.

[21] Hosoya T, Kawamoto H, Saka S. J Anal Appl Pyrolysis 2007;78:328-36.

[22] Rath J, Steiner G, Wolfinger MG, Staudinger G. J Anal Appl Pyrolysis 2002;62:83-92.

[23] Colomba DB. J Anal Appl Pyrolysis 1998;47:43-64

[24] Varhegyi G, Antal MJ, Jakab E, Szabo P. J Anal Appl Pyrolysis 1997;42:73-87.

[25] Bilbao R, Mastral JF, Aldea ME, Ceamanos J. J Anal Appl Pyrolysis 1997:39:53-64

[26] Safi MJ, Mishra IM, Prasad B. Thermochim Acta 2001;412:155-62.

[27] Branca C, Blasi CD. Fuel 2004;83(1):81-7.

[28] Fang MX, Shen DK, Li YX, Yu CJ, Luo ZY, Cen KF. J Anal Appl Pyrolysis 2006;77:22-7.

[29] Blasi CD, Branca C, Santoro A, Hernandez EG. Combust Flame 2001;124: 165-77.

[30] Liu NA. J Anal Appl Pyrolysis 2002;63:303-25.

[31] Ramiah MV. J Polym Sci 1970;14:1323-37.

[32] Blasi CD. J Anal Appl Pyrolysis 1998;47:43-64.

[33] Dung QT, Rai C. Fuel 1978;57:1379-89.

[34] Rath J, Staudinger G. Fuel 2001;80:1379-89.

[35] Caots AW, Redfern JP. Nature 1964;201:68.

[36] Song CC, Hu HQ, Zhu SW, Zhu YH. J Fuel Chem Technol 2003;31:311-6.

[37] Spearpoint MJ. NIST GCR 1999;99-975.

[38] Kenneth MB, Mathew JH. Fuel 2003;82:1633-44.

[39] Simms DL. Combust Flame 1960;4(4):293-300.

[40] Simms DL, Margaret L. Combust Flame 1967;11:377-88.

[41] Martin S. Diffusion-controlled ignition of cellulosic materials by intense radiant energy. In: Tenth symposium (international) on combustion. The Combustion Institute; 1965. 